\title{
História e imprensa: reconstituindo práticas de mulheres educadoras e empreendedoras na imprensa do interior potiguar
}

\author{
Manoel Pereira da Rocha Neto* \\ Laís Karla da Silva Barreto** \\ Isabel Cristine Machado de Carvalho***
}

\author{
Palavras-chave: \\ Gênero \\ Jornalismo \\ Empreendedorismo
}

\begin{abstract}
Resumo: A presente pesquisa tem como objetivo fazer uma análise da participação de mulheres educadoras na imprensa norte-rio-grandense, em particular na cidade de Caicó/RN, localizada no sertão potiguar. Neste artigo, destacamos a atuação de Georgina Pires (fundadora) e Dolores Diniz (gerente), mulheres empreendedoras que fundaram e administraram um jornal feminino, o Jornal das Moças, periódico que circulou de 1926 a 1932. Por meio de pesquisas em acervos particulares e públicos, como bibliotecas de instituições públicas e privadas, e através do levantamento bibliográfico sobre a temática, foi possível configurar a presença dessas mulheres e suas práticas jornalísticas na condução do jornal, considerado inovador e de vanguarda para os anos de 1920 no Rio Grande do Norte - um período em que a atuação da mulher estava restrita ao lar.
\end{abstract}

Keywords:

Gender

Journalism

Entrepreneurship

\begin{abstract}
The present research aims to analyze the participation of women educators in the North-Rio Grande press, in particular the city of Caicó/RN, located in the sertão of Potiguar. In this article we highlight the work of Georgina Pires (founder) and Dolores Diniz (manager), women entrepreneurs who founded and managed a women's newspaper, Jornal das Moças, a newspaper that circulated from 1926 to 1932. Through research in private and public collections As libraries of public and private institutions, as well as the bibliographical survey on the subject, it was possible to configure the presence of these women and their journalistic practices in the conduct of the newspaper considered innovative and avant-garde for the 1920s in Rio Grande do Norte in a period in That the woman's work was restricted to the home.
\end{abstract}

Recebido em 16 de maio de 2017. Aprovado em 02 de agosto de 2017.

\section{Introdução}

O presente artigo tem como objetivo analisar e reconstituir a participação de mulheres jornalistas e educadoras que aturam na imprensa do munícipio de Caicó, localizado no sertão do Rio Grande do Norte. Nesta pesquisa, enfatizamos e destacamos a participação da professora Georgina Pires, idealizadora e fundadora do Jornal das Moças, em parceria com a também educadora Dolores Diniz, que atuava com gerente da folha feminina. Essas mulheres, integrando um grupo ainda maior de moças, foram consideradas empreendedoras e ousadas ao levaram o Jornal das Moças adiante, promovendo a integração da mulher no cenário do interior potiguar, em meio a uma sociedade rural e dotada de aspectos patriarcais.

Com o objetivo de revelar e recuperar a história do Jornal das Moças e as práticas dessas mulheres, enveredamos em direção às fontes principalmente aos exemplares disponíveis para análise em arquivos públicos e privados. Essa trajetória foi ampliada nos acervos documentais e reportagens que configuram as ações das diretoras e dos conteúdos publicados na folha feminina. Nesse contexto, percorremos o Arquivo Público Estadual,

\footnotetext{
* Doutor em Educação pela Universidade Federal do Rio Grande do Norte (UFRN) e professor da Escola de Comunicação e Artes e do Programa de Pós-graduação em Administração da Universidade Potiguar (UnP).

** Doutora em Estudos da Linguagem pela Universidade Federal do Rio Grande do Norte (UFRN) e professora da Escola de Comunicação e Artes e do Programa de Pós-graduação em Administração da Universidade Potiguar (UnP).

*** Doutoranda em Ciências Sociais na Universidade Federal do Rio Grande do Norte (UFRN) e professora da Escola de Comunicação e Artes da Universidade Potiguar (UnP)
} 
a Biblioteca Câmara Cascudo, o Instituto Histórico e Geográfico do Rio Grande do Norte, a Biblioteca Central Zila Mamede (da Universidade Federal do Rio Grande do Norte), além dos exemplares disponíveis do Jornal das Moças no Campus da Universidade Federal do Rio Grande do Norte (UFRN) na cidade de Caicó.

Pesquisando a história das mulheres na imprensa do Rio Grande do Norte, encontramos a contribuição de Úrsula de Barros Garcia, em 1890. Ela colaborou com o jornal Rio Grande do Norte (1890-1896), que circulou em Natal. De acordo com Cascudo (1977, p. 81), no “[...] período de 1890 a 1896, o Doutor Amintas Barros, pai de Úrsula, fez parte da direção do referido jornal e a sua filha escreveu crônicas e críticas naquele periódico”.

Segundo Fernandes (1998, p. 91-92), o referido periódico era semanal, e a sua primeira edição é datada de 21 de abril de 1890: "Era um jornal com ideias republicanas. Em fevereiro de 1892, começaram a figurar como seus redatores ostensivos os doutores A. de Amorim Garcia, José Gervásio e Amintas Barros”.

No tocante à imprensa feminina no estado, em meados do século XX, surgiram periódicos como A Esperança (1903-1909), folha literária manuscrita, produzida por um grupo de jovens mulheres, que tinha à frente as professoras Izaura Carrilho e Dolores Cavalcante, na cidade de CearáMirim/RN; e o Via Láctea (1914-1915), revista literária em formato de apostilha, editada pelas primas Palmyra Wanderley e Carolina Wanderley, em Natal/RN. Finalmente, em 1926, a professora Georgina Pires fundou, em Caicó/RN, o Jornal das Moças, com a colaboração da gerente Dolores Diniz, da professora Júlia Medeiros e de um grupo de mulheres daquela cidade.

No Brasil, o ápice da imprensa feita pelas mulheres aconteceu no período de 1850 a 1910 . Nessa época, os impressos direcionados para as mulheres ganhavam espaço na imprensa em geral, principalmente na carioca, onde jornais como: "O Jornal das Senhoras (1852), Belo Sexo (1862), Biblioteca das Senhoras (1874), O Bisbilhoteiro (1889), Eco das Damas (1879-1882), Recreio do Belo Sexo (1856), Recreio das Moças (1876-1877),
O Direito das Damas (1882) e tantos outros circularam" (MORAIS, 1996, p. 109).

De acordo com Buitoni (1986, p. 37), o primeiro jornal de "[...] caráter feminino no Brasil nasceu no Rio de Janeiro e se chamava O Espelho Diamantino (1827). Esse periódico, lançado em 1827, continha política, literatura, belas-artes e modas". Eram os primeiros passos da participação da mulher na imprensa do Brasil. Acerca desse cenário da produção de jornais de textos jornalísticos durante o século XIX, a pesquisadora Barbosa (2007, p. 13), estudando a trajetória de vários jornais, menciona em seu estudo que: "A tarefa da história não é, pois, recuperar o passado tal como ele se deu, mas interpretá-lo. A partir dos sinais que chegam até o presente, cabe tentar compreender a mensagem produzida no passado dentro de suas próprias teias de significação".

Sentidos e representações sociais que são interpretados por meio dos escritos jornalísticos de vários jornais que circularam nos anos do século XIX e início do século XX, assim como o Jornal das Moças. Muitos jornais foram fundados e outros desapareceram com o tempo, principalmente os femininos.

Sobre o jornal como fonte histórica, Capelato (1994, p. 13) assinala que: "[...] é fascinante ler a história através dos jornais. Em cada página nos deparamos com aspectos significativos das vidas de nossos antepassados, que permitem recuperar suas lutas, ideias, compromissos e interesses".

Sobre os jornais femininos, Duarte (2016) afirma que alguns jornais tiveram vida efêmera. Todavia, muitos periódicos tiveram êxito, assim como os jornais gerenciados pelas professoras Georgina Pires e Dolores Diniz:

$$
\begin{aligned}
& \text { Se era comum os jornais sucumbirem } \\
& \text { após o segundo ou terceiro ano de vida, } \\
& \text { vencidos pelas dificuldades inerentes ao } \\
& \text { empreendimento, outros - muitos outros } \\
& \text { - tiveram vida longa. Como A Mai de } \\
& \text { família e Echo das Damas, ambos do Rio } \\
& \text { de Janeiro, que circularam durante nove } \\
& \text { anos ininterruptamente, de } 1879 \text { a } 1888 \\
& \text { [...]. (DUARTE, 2016, p. 19). }
\end{aligned}
$$

Desse modo, percebemos que literatura e jornalismo andavam juntos nesse dado período 
histórico, como assinala Buitoni (1986, p. 38): "literatos ora transformavam-se em jornalistas e vice-versa". Outras publicações surgiram, por exemplo, A Estação (1879-1904). Com excelente figurino e bem impressa, é considerada uma das mais importantes revistas femininas do final do século XIX. Há, ainda, A Mensageira (1897-1900), de São Paulo, e a Revista da Semana (1901), do Rio de Janeiro.

A publicação Kosmos (1904), além de contar com grandes nomes da literatura em suas páginas, tinha excelente apresentação gráfica. "Três títulos críticos, O Malho (1902), Fon-Fon (1907) e Careta (1908), vieram introduzir novas formas de linguagem humorística. Calixto, J. Carlos e Nair de Tefé, sob o pseudônimo de Rian, faziam caricaturas da sociedade carioca" (BUITONI, 1986, p. 42-43).

Em meados de 1914, surgiu, no Rio de Janeiro, a Revista Feminina, que circulou até 1936. Essa publicação foi o exemplo perfeito da vinculação entre a imprensa/indústria e a publicidade nascente, pois deve sua existência a uma bem-montada sustentação comercial - hoje defasada, mas que logrou êxito naquela época (BUITONI, 1986).

O Jornal das Moças e a Revista Feminina (1914) são impressos com características e estruturas organizacionais de uma "pequena empresa de comunicação", salientando-se as devidas proporções relativas à época. É bem verdade que esses veículos de comunicação eram de pequeno porte e diferentes dos grandes grupos de comunicação dos nossos dias. Entretanto, suas editoras já estavam sintonizadas com o advento da modernidade e da industrialização nascentes, contribuindo para que esses impressos se tornassem inovadores para os anos de 1920.

O Jornal das Moças era semanal e se dedicava ao interesse feminino. Sua circulação iniciou no dia 07 de fevereiro de 1926, na cidade de Caicó. Além de ser editado pela professora Georgina Pires e gerenciado por Dolores Diniz, o periódico contava também com a colaboração das redatoras Júlia Medeiros, Santinha Araújo, Julinda Gurgel, entre outras mulheres letradas da cidade de Caicó. Essas mulheres escreviam sobre literatura, humorismo e críticas.
Além da forte presença de mulheres, a folha contava também com a colaboração de redatores masculinos, como Renato Dantas, Janúncio Bezerra da Nóbrega e José Gurgel de Araújo. No que se refere às técnicas gráficas, o jornal se enquadrava nos padrões dos grandes jornais do Rio Grande do Norte da época - por exemplo, os periódicos A República, de Natal, e o Jornal do Seridó (19271929), de Caicó.

O Jornal das Moças era tabloide, com $28 \mathrm{~cm}$ de largura por $38 \mathrm{~cm}$ de altura, três colunas em cada página - as primeiras edições tinham o formato de duas colunas apenas - e impresso em papel jornal, com folhas soltas dobradas em forma de caderno. O periódico mantinha uma redação permanente e sua distribuição era feita através de venda avulsa nas bancas e por assinatura - sendo esse fato inédito para um jornal feminino no Rio Grande do Norte, visto que os jornais editados por mulheres, em sua grande maioria, eram manuscritos.

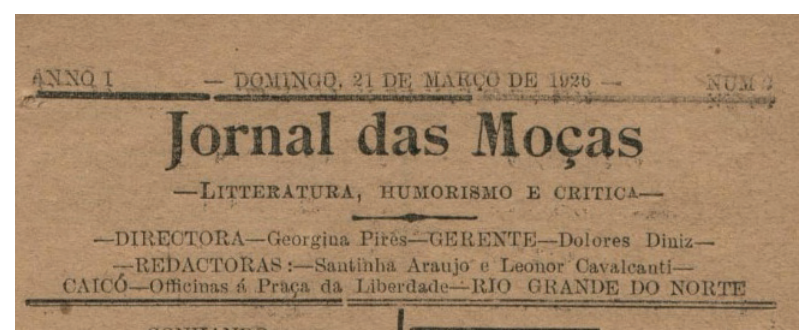

Figura 1 - Jornal das Moças (Diretora Georgina Pires e Gerente Dolores Diniz)

Fonte: Acervo particular de Nemias Gurgel

Desse modo, o tabloide de Caicó já utilizava técnicas jornalísticas, como a diagramação, formato de duas e três colunas, distribuição nas bancas da cidade, como também as assinaturas de seus exemplares. "As assinaturas tinham os seguintes valores: anual, 10 mil réis; semestral, 8 mil réis; trimestral, 4 mil réis; e a venda avulsa custava 200 réis" (MELO, 1987, p. 28).

\section{A presença de Georgina Pires}

Fundar um veículo que fosse o eixo norteador do pensamento das mulheres da cidade de Caicó não foi tarefa fácil para a professora Georgina Pires, filha de família tradicional daquela 
região. Seu espírito empreendedor e ousado para os padrões sociais vigentes tornou público o pensamento da mulher caicoense quando fundou, naquela cidade, o Jornal das Moças, aos 24 anos de idade. Georgina Pires nasceu em Caicó, no dia 13 de julho de 1902, sendo filha de Serafina de Araújo Pires Ferreira e do médico José da Silva Pires Ferreira, filho de português e conhecido na cidade com Dr. Pires, considerado, por muitos caicoenses, como o primeiro médico da cidade e um homem de bom coração - como assinala Nóbrega (1981):

Apóstolo da caridade, nunca deixou voltar de sua porta um cliente porque não tinha dinheiro. Amava a pobreza [...], exercia sua profissão em todos os municípios das adjacências, bem como nos da Paraíba. Na sua época, era muito difícil um médico naqueles sertões. (NÓBREGA, 1981, p. 61).

O pai da Georgina deixou exemplo de caráter, caridade, honestidade e nobreza aos filhos do Seridó. Nóbrega (1981, p. 61-62) assinala ainda que o "[...] Dr. José Augusto Bezerra de Medeiros, quando criança, deveu a sua vida ao Dr. Pires, que o salvou, muito doente que estava. A senhora Serafina Pires morreu jovem, aos 31 anos de idade, quando Georgina Pires se encontrava com cinco anos". A função de criar os oitos filhos da família Pires ficou a cargo da criada da família, Maria Angélica, batizada de mãe preta, por causa da cor de sua pele - como era comum naquela época. Sobre este fato, Nóbrega (1978) assinala que Angélica:

[...] se transformou em mãe preta devido o carinho e desvelo com que tratou as crianças. Daí a estima e veneração de todos. Com a missão de criar os filhos do Dr. Pires, mãe preta legou aos seus filhos adotivos os sentimentos mais puros da grandeza moral. Sempre estava presente a qualquer "ai" dos seus tutelados. (NÓBREGA, 1978, p. 55).

A professora Georgina Pires foi homenageada na edição inaugural do Jornal das Moças, através da coluna intitulada "perfil", assinada pela colega colaboradora e redatora que utilizava o pseudônimo de "Violeta":
Quando vai à igreja, com seu porte de rainha, os seus olhos claros, grandes cismadores, tem o esplendor das cousas infinitas! Sua tez morena e acentinada, suas mãos cruzadas sobre o peito, seus lábios murmurando uma oração, têm o palor das santas quando oram. Os seus dentes lembram as lindas pérolas de Ophyr. Alma de criança, coração feito para o amor; ama com delírio o seu ideal, sonho querido de sua mocidade. (VIOLETA, 1926, p. 4).

As palavras de sua colega Violeta traduzem as características físicas, a religiosidade e a personalidade forte e idealista da professora Georgina Pires, que obteve uma educação fora dos padrões da maioria das mulheres da sua terra. Georgina estudou na Escola Normal da Paraíba, em João Pessoa, em 1920, incentivada pelo seu pai. Retornou a Caicó após receber o título de professora. Chegando a sua terra natal, foi ensinar no Colégio Santa Teresinha do Menino Jesus, da Congregação Filhas do Amor Divino.

Sua passagem na citada instituição foi efêmera - atuou como professora aproximadamente cinco anos -, pois Georgina Pires, após voltar da Paraíba com ideias escolanovistas, logo se deparou com a pedagogia tradicional. Por isso abandonou a instituição, por não concordar com os métodos tradicionais da referida congregação.

Por fim, Georgina Pires também deixou o Jornal das Moças, para se casar com Janúncio Bezerra da Nóbrega. A edição de 15 de agosto de 1926 do citado periódico registra em suas páginas que o Sr. Janúncio Bezerra da Nóbrega, futuro marido de Georgina, viajava para a sua terra natal, a cidade de Acari /RN, com o objetivo de participar da festa da padroeira daquele município, qualificando-o como colaborador do jornal: "A fim de assistir a festa da padroeira de Acari, seguiu na segunda-feira última (9 de agosto de 1926) o Sr. Janúncio Bezerra, um dos talentosos colaboradores desta folha (JORNAL DAS MOÇAS, 1926, p. 2).

O escritor Janúncio Bezerra da Nóbrega se fez presente nas páginas do jornal, sendo um dos poucos do sexo masculino a colaborar com a folha. De acordo com Melo (1987, p. 28), outro homem também colaborou para o jornal, o Sr. 
Renato Dantas. Na coluna "Notas sociais", da edição de 23 de maio de 1926 (JORNAL DAS MOÇAS, 1926c), é publicada uma nota em que Janúncio Bezerra da Nóbrega, ainda solteiro, responde a um questionário que, semanalmente, era proposto às pessoas importantes da cidade de Caicó. Indagado sobre "o que é um olhar", ele responde nas páginas do Jornal das Moças:

Sempre pensei que ele é veículo condutor da expressão viva da alma. Há tanta eloqüência $[$ sic] num modo de olhar. Às vezes, é tão significativo, que dentro de um minuto ele é tristeza e é alegria, é amor e disgosto [sic]. É a pergunta e é a resposta d’alma, é uma promessa e é uma negação. É em suma, a confissão do estado d’alma. (NÓBREGA, 1926, p. 4).

Sobre o noivado, a edição de 15 de agosto de 1926 do Jornal das Moças publicou uma nota intitulada "Pensamento", que versa sobre a importância da cerimônia: "O noivado, pela sublime e dignificante satisfação que reina severamente nos corações dos noivos, torna-se um dos elementos de primeira necessidade para a condição da vida" (JORNAL DAS MOÇAS, 1926, p. 3).

A professora Georgina Pires casou-se com o Sr. Janúncio Bezerra da Nóbrega no dia 22 de fevereiro de 1927, na Igreja matriz de Caicó. Após o casamento, a professora dedicou-se à sua família. Inicialmente, permaneceu em Caicó; em seguida, mudou-se para Mossoró/RN e depois para Acari/ RN. Ela teve 11 filhos, dos quais oito se criaram. Georgina Pires faleceu em Natal, no dia 25 de junho de 1990, aos 88 anos. O jornal Tribuna do Norte, edição de 29 de junho de 1990, publicou uma nota sobre a sua morte na coluna "Fatos e figuras do Seridó", assinada pelo jornalista Carlos Magno Dantas:

Faleceu em Natal, no último dia 25, a professora Georgina Pires Ferreira da Nóbrega, 88 anos, nascida em Caicó e viúva do historiador, escritor e técnico agrícola Janúncio Bezerra da Nóbrega [...]. Dona Georgina foi professora [...] era filha do casal Serafina de Araújo Pires e José da Silva Pires Ferreira, na intimidade conhecido como Dr. Pires, o primeiro médico de Caicó, cujo nome ainda é lembrado hoje, por todo Seridó, pelo desprendimento e assistência aos mais necessitados de toda a região. Dona Georgina deixou oito filhos. (TRIBUNA DO NORTE, 1990, p. 11).

Essa professora teve uma trajetória de vida pautada nas reivindicações dos direitos das mulheres. Ao fundar o Jornal das Moças, veículo irradiador dos pensamentos femininos, ela buscou conquistar direitos sociais e se fazer ouvir pela sociedade norte-rio-grandense. É nesse mesmo sentido que, ao desempenhar as suas práticas pedagógicas, enquanto lecionava geografia no Colégio Santa Teresinha, ela discorda dos métodos pedagógicos da citada instituição. Por outro lado, por opção, dedicou-se ao privado, vivendo para a sua família.

À frente do Jornal das Moças, cumpriu o seu papel, junto com as demais colaboradoras, ao propagar as suas ideias e críticas com relação às normas sociais vigentes naquele período. Mesmo optando em viver para a sua família, sempre fez o que teve vontade e teve a sua vida nos dois polos distintos, o público e o privado.

Seu comportamento era de recato, assim como o da gerente Dolores Diniz, que também viveu nos dois espaços sociais. Desse modo, restava às mulheres essas alternativas, tanto no espaço público como no âmbito do lar. Essas mulheres fizeram uso do periódico para propagar os direitos das mulheres, mas também utilizaram táticas para articular a sua família, de modo mais sutil.

\section{Dolores Diniz: gerente da folha feminina}

A gerente do Jornal das Moças, Dolores Diniz, desempenhou sua função com esmero e dedicação. Estava sempre à frente do jornal, juntamente com a professora Georgina Pires. Essas mulheres imprimiam nos periódicos femininos do Rio Grande do Norte, guardadas as devidas proporções, aspectos de empresa, como os grandes jornais norte-rio-grandenses. Essa tarefa exigiu, 
de suas editoras, dedicação e perseverança, para administrar um jornal pequeno, mas que nasceu da abnegação e do desejo da mulher caicoense em se fazer ouvir. No que concerne aos seus escritos no “jornalzinho", Dolores Diniz descreve, em um dos artigos, a sua concepção sobre a mulher:

Não creio, como muita gente, que é preciso ter os lábios e faces bem pintados, elegância, pose de melindrosa, ou quaisquer desses predicados que exige a vaidade exagerada; tudo isso pode desaparecer na continuação do tempo. O encanto da mulher consiste unicamente em ser virtuosa. Pode concorrer também em certo ponto de vista, a polidez, a modéstia limitada, simplicidade dos modos, não cultivada por isso nenhuma vaidade. (DOLORES, 1926a, p. 3).

O conceito de Dolores Diniz traduz a sua personalidade, segundo os depoimentos e entrevistas de seus familiares e amigos. Era simples, elegante, gentil, sorridente e idealista. A gerente da folha nasceu em Caicó, no dia 5 de outubro de 1901, sendo filha do Sr. Sabino Policarpo Diniz e da Sra. Maria Benigna Vale. Dolores Diniz não foi professora diplomada. Ela foi alfabetizada em sua própria casa e se tornou professora particular. Ensinava em sua residência. Sempre foi apaixonada pela educação. Aos 15 anos, já redigia para um jornalzinho manuscrito denominado A Escola (1916-1917), órgão comprometido com a educação das crianças da cidade. Encontramos registros desse jornalzinho educativo no jornal O Binóculo (19161918), editado em Caicó, conforme ilustra esta citação publicada em 8 de agosto de 1917:

A Escola (1916-1917) é um jornalzinho manuscrito, editado nesta cidade, tendo como redatoras as gentis senhoritas: Assunpção de Medeiros, Julinda Gurgel - também foi colabora do Jornal das moças (1926-1932), Dolores Diniz, Severina de Brito, Arthemia Dantas e Theodora Vale. (O BINÓCULO, 1917, [s.p.])

Como professora particular, Dolores Diniz alfabetizou todos os seus filhos. A edição do Jornal das Moças de 28 de fevereiro de 1926 traz, em suas páginas, o perfil de Dolores Diniz:

Pequenina, gentil e faceira. Nos seus lábios mimosos e coralinos, vive sempre a adejar um sorriso feiticeiro. Olhos negros, como a noite escura, têm lampejos de estrela e às vezes languidez de amor [...]. A sua meia cabeleira preta e anelada que dava um encanto especial à sua cabecinha redonda e sedutora. (JORNAL DAS MOÇAS, 1926, p. 4).

Desempenhando a função de gerente, desde a fundação do Jornal das Moças, Dolores Diniz saiu dos quadros do periódico em virtude de seu casamento com o comerciante de Caicó, o Sr. Aderson Soares, proprietário de curtume, de uma loja de tecidos e do Hotel Avenida, em Caicó. O enlace aconteceu na residência do Coronel Luiz Agatângelo de Brito, no dia 10 de agosto de 1926, às 17 horas, segundo reportagem do Jornal das Moças. A edição desse jornal, datada de 7 de agosto de 1926, publicou uma nota que trata da saída da sua gerente, com o título "Dolores Diniz":

A todas que trabalham neste jornal causou sincera tristeza a retirada da nossa distinta companheira Dolores Diniz, que vinha exercendo com toda dedicação e inteligência o lugar de gerente desde o primeiro número. Levando os nossos justos agradecimentos cheios de nossas saudades à querida amiguinha que por tanto tempo esteve conosco, fazemos votos pela sua felicidade pessoal e de seu novo estado. (JORNAL DAS MOÇAS, 1926, p. 4).

Dolores Diniz não apenas deixou o espaço público para se dedicar ao seu esposo, ela também deixou o estado e foi morar no vizinho, a Paraíba, na cidade de Campina Grande/PB. O motivo da mudança de estado foi devido à crise do comércio em Caicó - enquanto a cidade de Campina Grande, por sua vez, prosperava na mesma área.

O seu antigo cargo de gerente no Jornal das Moças foi ocupado pela colaboradora Santinha Araújo. Este fato é notado a partir da edição de $\mathrm{n}^{\circ} 30$ do jornal, datada de 15 de agosto de 1926. 
$\mathrm{Na}$ primeira página, logo abaixo do logotipo do jornal, aparece o nome de Santinha Araújo como a nova gerente da folha.

A referida matéria foi publicada na segunda página da edição de número 30, datada de 15 de agosto de 1926, cinco dias após o casamento de Dolores Diniz. Com o título "Enlace de Dolores", a reportagem retrata o casamento da ex-gerente do jornal, que aconteceu no dia 10 de agosto de 1926. Segundo o periódico, após a cerimônia foi oferecido um chá: "Ȧ noite foi oferecido aos convidados numa mesa artisticamente preparada um excelente chá, seguindo-se as danças que se prolongaram até às 21h:00 [sic]. A distinta família do Coronel Luiz Agatângelo de Brito a todos cativou pelo seu trato fidalgo" (JORNAL DAS MOÇAS, 1926, p. 2).

O jornal encerra o relato do casamento de Dolores Diniz prestando uma homenagem à sua editora. Segundo a matéria, sua atuação como gerente foi de êxito, de estabilidade e de aceitação perante a sociedade de Caicó, em uma época em que se tornar figura pública era direito apenas dos homens: "A nossa querida ex-companheira, a quem o Jornal das Moças deve o melhor de sua estabilidade, de seu brilho e de sua aceitação, levamos os nossos sinceros votos de felicidades" (JORNAL DAS MOÇAS, 1926, p. 2).

A atuação de Dolores Diniz na folha não se limitou a gerenciar. Em outra matéria, na mesma edição da reportagem do seu casamento, o jornal publicou o seu discurso na ocasião do "Festival Lítero-artístico", evento promovido pelo Jornal das Moças e realizado no teatro Avenida. Na abertura do Festival, ela inicia a sua fala enfatizando a importância daquele jornal para a sociedade norterio-grandense:

O Jornal das Moças é uma bela cintilação da inteligência feminina, porém, é, mais ainda, um padrão de trabalho de amor e de virtude. Em pleno século XX, meus senhores e minhas senhoras, quando o liberalismo feminino se levanta [...] a moça de Caicó conseguiu esse triunfo, essa idéia [sic], esse pensamento com a criação do seu jornal. (DOLORES, 1926b, p. 2).
No seu discurso, observamos o desejo de Dolores Diniz com relação à folha que gerenciava. $\mathrm{Na}$ ocasião, ela destacou a importância de divulgar para toda a cidade de Caicó aquele jornal, que era a voz da mulher, e solicitou a cooperação de toda a sociedade, principalmente as moças de Caicó:

A cooperação é, porém, o fundamento do seu pregresso (do jornal). A dinâmica de sua vida é a razão de sua existência no povir. Assim, pois, precisamos do carinho do vosso apoio, da benevolência da vossa simpatia. Por um princípio de sociabilidade entre a moça norte-rio-grandense, contamos com a vossa propaganda, com o vosso grito de ânimo e de coragem, a fim de que seja verdade o intercâmbio intelectual, moral e social, da mocidade feminina, sempre cheia de esperanças vigorosas e de aspirações verdadeiramente admiráveis. (DOLORES, 1926a, p. 2).

Dolores Diniz convida toda a sociedade que se fazia presente naquele evento, principalmente o público feminino, a levantar a bandeira em defesa do jornal, da sociabilidade das moças da cidade, como também do desenvolvimento da inteligência feminina norte-rio-grandense. E ela encontrava mulheres que atendiam ao seu pedido. Uma colaboradora do jornal, que assina como "Violeta", emite a sua opinião:

Foram dez dias de risos, esperanças e amores e ilusões. No meio de tanto encantamento em que os corações jovens se deixaram embriagar no perfume que envolve o ar nesses dias de gala, só uma coisa me fez triste e pensativa - não ter ido a [sic] festa do Jornal das Moças. (VIOLETA, 1926, p. 2).

Era o desejo das mulheres de Caicó de conquistar novos espaços na sociedade. A vida moderna exigia novas formas de comportamento. O jornal era um espaço privilegiado, pois chegava aos lares e levava consigo assuntos e discussões que transcorriam fora do espaço privado.

Nesse ínterim de agitação, em que tudo parecia novo, as mulheres, que eram educadas para o espaço privado, começaram a despertar 
suas inquietações para também participar daquele momento, que, até então, poucos tinham acesso: as "maravilhas da modernidade".

Esse espírito de modernidade está presente em um trecho do discurso de Dolores Diniz na abertura do Festival Lítero-artístico: "[...] queremos as alturas condoreiras, galgar nas asas do optimos, andar de braços com a evolução [...], que encontra apoio na civilização cosmogônica das grandes cidades" (DINIZ, 1926b, p. 2).

No entanto, apesar do discurso que aborda as questões femininas e o desejo de conquistar direitos sociais, a gerente abandona seu trabalho após o casamento. Afirmamos isso no sentido de opção pessoal, da vida privada, pois os espaços, conforme já foi abordado, eram distintos - ou seja, naquele recorte temporal, a mulher não exercia ainda a jornada dupla de trabalho no público e no privado.

A partir daquele momento, Dolores Diniz deixa o espaço público, conquistado através das suas práticas de escrita e, sobretudo, das suas práticas administrativas - função essa que, à época, era exercida exclusivamente fora do lar pelo homem, para dedicar-se ao casamento.

Esta atitude da ex-gerente do Jornal das Moças representa o caminho que a sociedade vigente daquele período estabelecia para os destinos das mulheres. Mesmo detentora de ideias e pensamentos que entravam em confronto com as normas sociais - como o direito de voz à mulher, por exemplo -, Dolores Diniz se fez calar.

O seu silêncio diante do abandono do espaço já conquistado de maneira competente, como afirmou a professora Georgina Pires, no artigo já citado do seu jornal, é reflexo dos mecanismos de controle social, de naturalização dos papéis. Sobre essa questão, Rocha-Coutinho (1994, p. 39) assinala:

A naturalização dos papéis atribuídos às mulheres tornou invisível a regulação de seus desejos, de sua vida, enfim, a violência simbólica de que elas são vítimas, ocultando as relações de poder que se estabelecem no interior da sociedade [...] os comportamentos de subordinação femininos ficam, então, emaranhados no cotidiano destas mulheres como forma natural de organização de suas vidas diárias, sem que muitas delas tomem consciência deste fato, ou seja, se a têm, lhe outorgam consenso exatamente porque são naturais.

No fragmento, está claramente colocado que a naturalização é imposta de maneira invisível no interior da sociedade. O comportamento de subordinação é intrinsecamente emaranhado no cotidiano de uma dada sociedade, de modo "natural", normal, sem que muitas mulheres se deem conta.

Na Paraíba, Dolores Diniz constituiu uma família de quatro filhos: Maria Augusta, Maria Dulce, Fernando Augusto, Maria Aline e Maria do Céu - essa última falecida quando criança. Além do ofício de mãe, Dolores Diniz também exerceu a função de costureira para ajudar no orçamento doméstico, pois os negócios do seu marido estavam em dificuldades. Devido a isso, no $1^{\circ}$ de maio de 1938, Dolores Diniz mudou-se para a capital paraibana com sua família. O seu marido Aderson Soares, juntamente com o cunhado, abriram uma saboaria, batizada de Saboaria Cearense - que produzia o "Sabão maravilha”. A gerente faleceu em 5 de abril de 1999, aos 97 anos de idade, em João Pessoa, na Paraíba.

\section{Considerações finais}

Movidos pelo desejo de pesquisar o Jornal das Moças, foi-nos possível, no presente artigo, entender a atuação da mulher como empreendedora e comunicadora social, assim como também investigar as suas práticas de escritas e de gestão, configuradas na cultura social do município de Caicó, no sertão do Rio Grande do Norte, em uma época em que a atuação das mulheres na sociedade estava restrita ao universo privado - ou seja, ao lar, com o objetivo de cuidar do marido e educar os filhos.

Ao pesquisar as práticas de Georgina Pires, fundadora do Jornal das Moças, e da gerente do jornal, Dolores Diniz, foi possível trazer para o panorama histórico, professoras, literatas e poetisas que utilizaram as práticas de leitura e escreveram 
suas reivindicações e anseios, fazendo e refazendo uma nova história, a história das pessoas comuns.

Durante a pesquisa e catalogação de vários jornais, entre eles o Jornal das Moças, notamos que o século $\mathrm{XX}$ foi um período fértil para a imprensa local, sobretudo para a participação das mulheres na imprensa local, espaço até então predominantemente masculino. As mulheres produziram jornais e revistas nas primeiras décadas do século XIX em Natal e no interior do estado do Rio Grande do Norte.

Os resultados encontrados durante esta pesquisa contribuem para uma visão técnica e crítica desses jornais femininos, em especial, do Jornal das Moças, e da administração e empreendedorismo das suas fundadoras e editoras.

Nesse contexto, é possível afirmar que as mulheres ainda buscam novos campos de trabalho, em todas as profissões, e desejam conquistar novos espaços, principalmente aqueles responsáveis por formar opinião, como é a imprensa. Nesse sentido, podemos afirmar que há o sentimento de vanguarda na luta em prol dos direitos das mulheres no Rio Grande do Norte: desde o século XIX, com Nísia Floresta; a conquista de direitos antes negados, como o voto, com a norte-rio-grandense Celina Guimarães Vianna, em 1927; e o direito a exercer cargos públicos, como foi o caso da potiguar Alzira Soriano, um ano depois, em Lajes/RN.

Tudo isso permeia ainda mais o nosso desejo de seguir adiante na pesquisa, contribuindo para a compreensão de uma história mais ampla, que engloba não apenas os heróis da historiografia tradicional, mas a história de pessoas e fatos considerados subalternos pela História, em um dado período e em um dado lugar. Histórias de vida de professoras, suas tensões e suas práticas empreendedoras e de escrita no Jornal das Moças. Essas mulheres eram situadas no espaço social, a cidade de Caicó, na década de 1920, época de transformações políticas e sociais no Rio Grande de Norte. As histórias de vida das professoras Georgina Pires e Dolores Diniz têm a mesma importância, sob a ótica da Historia Cultural. Portanto, a distinção feita tradicionalmente entre o que é central e o que é periférico perde completamente o sentido.

\section{Referências}

BARBOSA, M. História cultural da imprensa: Brasil 1800-1900. Rio de Janeiro: Mauad X, 2007.

BUITONI, D. S. Imprensa feminina. São Paulo: Ática, 1986. (Série Princípios).

CASCUDO, L. da C. O livro das velhas figuras: pesquisa e lembranças na história do Rio Grande do Norte. Natal: Instituto Histórico e Geográfico do Rio Grande do Norte, 1977.

CAPELATO, M. H. R. A imprensa na história do

Brasil. 2. ed. São Paulo: Contexto/EDUSP, 1994.

DINIZ, D. Respostas às interrogações do número retrasado, dirigidas ao corpo redacional do Jornal das Moças. Jornal das Moças: Literatura, Humorismo e crítica, Caicó, 4 abr. 1926a, p. 3.

Discurso. Jornal das Moças: Literatura, Humorismo e crítica, Caicó, 15 ago. 1926b, p. 2.

DUARTE, C. L. Imprensa feminina e feminista no Brasil: século XIX. Belo Horizonte: Autêntica, 2016.

FERNANDES, L. A imprensa periódica no Rio Grande do Norte de 1832 a 1908. 2. ed. Natal: Fundação José Augusto; Sebo vermelho, 1998.

\section{GURGEL, N. Acervo particular.}

JORNAL DAS MOÇAS: Literatura, Humorismo e crítica. Caicó, 7 fev. 1926, p. 4.

.28 fev. 1926a, p. 4.

.04 de abril de 1926b, p. 3.

23 maio 1926c, p. 4.

.7 ago. 1926d, p. 4.

15 ago. 1926 e, p. 2.

MELO, M. R. de. Dicionário da imprensa no Rio Grande do Norte: 1907-1987. São Paulo: Cortez; Natal: Fundação José Augusto, 1987. 
MORAIS, M. A. C. de. Leituras femininas no século XIX. 1996. Tese (Doutorado em Educação)

- Faculdade de Educação, Universidade Estadual de Campinas, Campinas, 1996.

NÓBREGA, J. B. da. Nota. Jornal das Moças: Literatura, Humorismo e crítica, Caicó, 23 maio 1926, p. 4.

Saudades do Seridó. Natal: Clima, 1978.

Revivendo o Seridó. Natal: Clima, 1981.

Denodados seridoenses. Natal: Clima,
O BINÓCUlO. Periódico da cidade de Caicó, Rio Grande do Norte, 8 jul. 1917, [s. p.].

ROCHA-COUTINHO, M. L. R. Tecendo por trás dos panos: a mulher brasileira nas relações familiares. Rio de Janeiro: Rocco, 1994.

TRIBUNA DO NORTE, Natal, 29 jun. 1990, p. 11.

VIOLETA. Nota sobre Georgina Pires. Jornal das Moças: Literatura, Humorismo e crítica, Caicó, 7 fev. 1926, p. 4.

1983. 